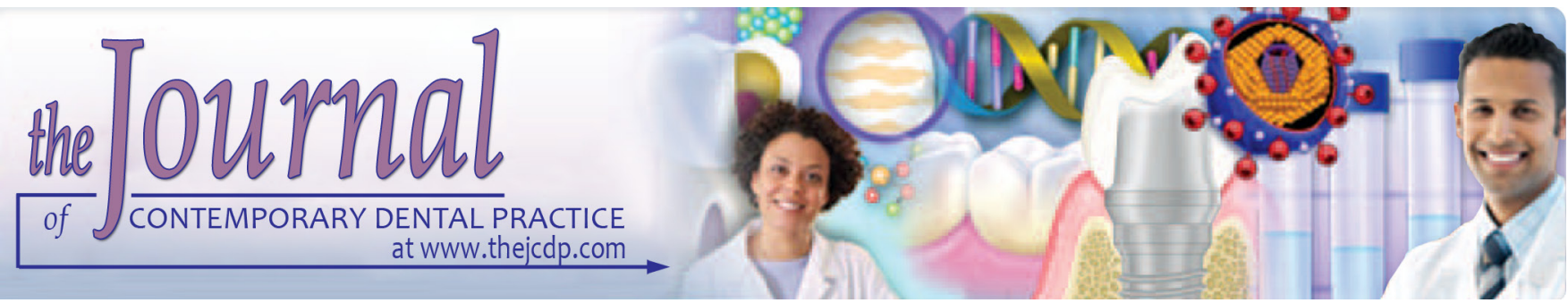

\title{
Effect of Er: YAG Laser, Sandblast and Several Types of Universal Bonding on Shear Bond Strength of Zirconia Ceramic to Composite Resin
}

\author{
${ }^{1}$ Loghman R Sofi, ${ }^{2}$ Reza Fekrazad, ${ }^{3}$ Mahdi Akbarzadeh, ${ }^{4}$ Marjan Maleki
}

\begin{abstract}
Aim: The purpose of this study was to investigate the effect of Erbium-doped yttrium aluminium garnet laser laser (Er: YAG laser), sandblast and several universal bonding on the shear bond strength of zirconia ceramic to composite resin.

Materials and methods: In this experimental study, 96 Y-TZP disks were used. They were divided into six groups based on surface preparation: 1-Er: YAG laser + single bond universal/ 3M, 2-Er: YAG laser + all bond universal/bisco, 3-Er: YAG laser + G-premio bond/GC, 4-sandblast + single bond universal/3M, 5-sandblast + all bond universal/bisco, 6-sandblast + G-Premio bond/GC; in the next step, composite discs were cured on the surface of the zirconia discs and their shear bond strength was evaluated using a mechanical test machine (universal testing machine).
\end{abstract}

Results: Two-way ANOVA showed that the surface preparation had a significant statistical effect on shear bond strength $(p<0.001)$. There was no association between these two variables with regards to the interaction of bonding and surface preparation $(p=0.064)$. Tukey's test showed that the shear bond strengths in the sandblast type group did not differ significantly between the groups according to the type of universal bonding, as well as in the Er: YAG laser treated group by type Universal bonding which was not significantly different between the groups of single bond universal and all bond universal, but there was a significant difference between the groups in terms

\footnotetext{
${ }^{1,4}$ Department of Restorative Dentistry, School of Dentistry, Hamadan University of Medical Sciences, Hamadan, Iran

${ }^{2}$ Department of Laser Research Center in Medical Science, Tehran University of Medical Sciences, Tehran, Iran

${ }^{3}$ Department of Community Medicine and Modern Epidemiology Research Center, Tehran University of Medical Sciences, Tehran, Iran
}

Corresponding Author: Marjan Maleki, Department of Restorative Dentistry, School of Dentistry, Hamadan University of Medical Sciences, Hamadan, Iran, Telafax: (+98)9124438807, e-mail: dentistmarjan62@gmail.com of single bond universal and G-Premio, as well as all bond universal and G-Premio.

Conclusion: Based on the results, the preparation of Er:YAG laser is a more appropriate method for increasing bond strength when compared with sandblasting, and among the universal bonding, G-Premio is also more suitable for this purpose.

Clinical significance: The present data indicate that bond strength of laser preparation and G-Premio adhesive might be reliable for clinical application

Keywords: Er: YAG Laser, Sandblasting, Shear bond strength, Universal bonding.

How to cite this article: Sofi LR, Fekrazad R, Akbarzadeh M, Maleki M. Effect of Er: YAG Laser, Sandblast and Several Types of Universal Bonding on Shear Bond Strength of Zirconia Ceramic to Composite Resin. The Journal of Contemporary Dental Practice, October 2018;19(10):1246-1253.

Source of support: Nil

Conflict of interest: None

\section{INTRODUCTION}

In clinical conditions, as a result of insufficient strength of conventional ceramics and alumina base ceramics, ceramic with zirconia bases was introduced for the purpose of making all-ceramic restorations. Ceramicbased on zirconia is used for ceramic restorations because of its chemical stability, biocompatibility, proper compression strength, appropriate esthetic, reconstruction normal dental appearance and thermal expansion coefficient similar to hard tissues of the tooth. ${ }^{1}$ Because of the instability of pure zirconia, this material is used in the four-dimensional crystalline phase, which is partially stabilized with Yttrium oxide. ${ }^{2,3}$ The adhesion of zirconium restorations also has disadvantages in terms of band. One of these disadvantages is the need for resin cements containing monomer phosphate to cement ceramic restorations with zirconia bases. ${ }^{3}$ 
In earlier studies, it was found that indirect all-ceramic restorations require a durable and stable bond between cement and ceramic for long-term efficacy. ${ }^{4,5}$ The use of resin cements for bonding restoration to teeth, also provides restorative bond strength to the teeth in addition to improving retention and resistance to fracture of the restoration and increasing the marginal adaptation. If proper bonding between the restoration and tooth is not established, the retention and resistance reduces and leads to failure of the restoration, and with reduction of the marginal adaptation, the probability of secondary caries is also increased. ${ }^{6}$

Creating a micromechanical bond between the composite resin and ceramic zirconia requires the creation of internal surface roughness of ceramic to increase the surface available for penetration of the resin. In the case of Yttria stabilized tetragonal (Y-TPZ) zirconia ceramics, surface preparation with conventional methods, such as hydrofluoric acid etching, is often a dysfunctional method due to the lack of a glass phase in the structure of this material. ${ }^{4-6}$ In studies on reinforcing the shear bond of zirconia ceramic to resin composites, results have shown that sandblasting, lasers and universal bonding can be used to strengthen the bond. ${ }^{7}$

Erbium lasers were introduced as an alternative to conventional mechanical tools for cutting dental surfaces in dentistry. These lasers can absorb radiation energy at a range of 2.6 and $3 \mu \mathrm{m}$, which is the strongest water absorption range and the most important component of hard dental tissues. ${ }^{8,9}$ One of the family members of Erbium lasers, Er: YAG, is the mild infrared waves of this laser that has a significant abrasion effect on hard dental tissue. ${ }^{10}$ The energy released by this laser is well absorbed by hydroxyapatite and is more effective in removing dental hard tissues than other laser systems. This kind of laser is used for the removal of caries and cavity preparation and provides conditions for proper bonding. ${ }^{11}$

Sandblasting is another method for strengthening bond strength (air abrasion by aluminum oxide). It increases the bonding surface and surface roughness, and forms undercut on the ceramic surface. ${ }^{12,13}$ In this method, high-speed particles of aluminum remove weak ceramic phases and create surface irregularity that increase the surface and strengthen the bonding. ${ }^{14}$

Another major change that occurred during the Adhesive Dentistry century was the use of bonding systems. In this context, a substance called bonding agent which can connect two surfaces to each other, resist the separation of these two surfaces and transfer forces through the bond, is used. The use of a type of bonding system, called universal bonding, is one of the newest techniques used. The difference between this type of bonding system and previous techniques is that in this system, all components are in a bottle, and can be used with total etch and self-etch systems. ${ }^{15,16}$

Therefore, the present study aimed to investigate the effect of Er: YAG laser, sandblasting and single bond universal/3M bonding, All-bond universal/Bisco and G-premio bond/GC on the shear bond strength of zirconia ceramic to composite resin.

\section{MATERIALS AND METHODS}

In this experimental study, 96 Y-TZPs (VITA YZ GmbHGermany) were used. Discs with a diameter of $6 \mathrm{~mm}$ and a thickness of $2 \mathrm{~mm}$ were prepared by a copy milling technique using a milling machine and following the manufacturer's instructions. Subsequently, they were divided into six groups based on surface preparation:

\section{Group 1}

Surface preparation with Laser Er: YAG (FOTONA, Slovenia): 16 samples with an Er: YAG laser was used at a wavelength of $2940 \mathrm{~nm}$, frequency of $15 \mathrm{~Hz}$, energy of $200 \mathrm{mj}$ and a power of $3 \mathrm{~W}$. The pulse duration was 230 s. $^{17}$ One layer of single bond universal (3M ESPE, St, Paul, MN, USA) was applied on the samples, rubbed for 20s, and thinned with a gentle flow of water-air syringe for $5 \mathrm{~s}$, and cured with a light device LED (Kerr, CA, USA) with intensity of $1200 \mathrm{~mW} / \mathrm{cm}^{2}$ for 10 seconds.

\section{Group 2}

Surface Preparation by Er: YAG laser: 16 samples were used with aEr: YAG laser, with a wavelength of $2940 \mathrm{~nm}$, frequency of $15 \mathrm{~Hz}$, energy of $200 \mathrm{mj}$ and a power of 3 $\mathrm{W}$. The pulse duration was $230 \mu \mathrm{s}$. Two layers of all bond universal (Bisco, Schaumburg, IL, USA) were rubbed for $10-15$ s on each layer, and the layers were not cured. Then thinned with a gentle flow of water-air syringe for $10 \mathrm{~s}$ and cured with a light device LEDs with an intensity of $1200 \mathrm{~mW} / \mathrm{cm}^{2}$ for 10 seconds.

\section{Group 3}

Surface Preparation by Er: YAG Laser: 16 samples with Er: YAG lasers with the aforementioned characteristics in G1. One layer of G-Premio bonding (GC, Tokyo, Japon) was applied on the samples and rubbed for 10s, thinned with a gentle flow of water-air syringe for $5 \mathrm{~s}$, and cured with a light device LED with an intensity of $1200 \mathrm{~mW} /$ $\mathrm{cm}^{2}$ for 10 seconds.

\section{Group 4}

Surface preparation by sandblasting (Renfert $\mathrm{GmbH}$, Germany). A total of 16 samples were obtained in this group. Sandblasting was done using $25 \mu \mathrm{m}$ aluminum oxide particles for 10 seconds on a surface with a distance 
of $3 \mathrm{~mm}$ and a pressure of $30 \mathrm{psi}^{18}$ In the next step, one layer of single bond universal (3M ESPE, St, Paul, MN, USA) was applied on the specimens, rubbed for 20 seconds and thinned with a gentle flow of water-air syringe for 5 seconds, and cured with a light device LED with $1200 \mathrm{~mW} / \mathrm{cm}^{2}$ intensity for 10 seconds.

\section{Group 5}

Surface preparation by sandblast. A total of 16 samples were obtained in this group. Sandblasting was done with the aforementioned characteristics in G4. Then, two layers of all bond universal (Bisco, Schaumburg, IL, USA) were rubbed on each layer for 10 to 15 seconds on the specimens and was not cured between layers and thinned with a gentle flow of water-air syringe for 10 seconds with air and was cured with the light device LEDs with intensity of $1200 \mathrm{~mW} / \mathrm{cm}^{2}$ for 10 seconds.

\section{Group 6}

Surface preparation by sandblast. A total of 16 samples were obtained in this group. Sandblasting was done with the aforementioned characteristics in G4, and then one layer of G-Premio bonding (GC, Tokyo, Japon) was placed on samples for 10 seconds and thinned with a gentle flow of water-air syringe for 5 seconds and cured with a light device LED with an intensity of $1200 \mathrm{~mW} / \mathrm{cm}^{2}$ for 10 seconds. In the next step, nano-hybrid composite resin disks, Z250xt were made (3M ESPE, St, Paul, MN, USA) with a diameter of $3 \mathrm{~mm}$ and a thickness of $2 \mathrm{~mm}$ by compressing the composite into a transparent plastic mold on the slab Glass then cured on the surface of zirconia for 40 seconds using a light device with an intensity of $1200 \mathrm{mw} / \mathrm{cm}^{2}$. In the next step, shear bond strength was determined by Universal testing machine with a loading speed of $0.5 \mathrm{~mm} / \mathrm{min}$ and compared with each other. ${ }^{17}$

\section{Scanning Electron Microscope (SEM) Method}

First, the samples were prepared in small dimensions and bonded using a two-way carbon-conductive adhesive on a stub. Then, placed inside the ION SPUTTERING device for 2 minute in order to form gold coats on the surface and become conductive. Finally, the samples were put in the SEM machine, JEOL model JSM-840A, for imaging with application of $15 \mathrm{Kev}$ voltage, and images were taken by different magnification.

\section{Statistical Analysis}

Analysis was performed by Statistical Package for the Social Sciences (SPSS)-16 software. For comparison between the groups and considering that two surface preparation factors (Er: YAG laser and Sandblast) and universal bonding are independent variables, and to compare the mean shear bond strengths of the groups, two-way ANOVA and the Tukey complementary comparison were used. It should be noted that a normal distribution test was first performed using the Kolmogorov-Smirnov method. The significance level in all the tests was less than 0.05 .

\section{RESULTS}

\section{Evaluation of the Strength According to the Type of Surface Preparation}

Descriptive results regarding the shear bond strengths are presented in Table 1. The highest level of strength was observed for the G-Premio and laser group (25.58 \pm 4.82$)$ and the lowest was observed for the group prepared with Sandblast and all-bond universal (18.48 \pm 3.20$)$.

\section{Two-way Analysis of Variance}

According to the results in Table 2, surface preparation had a statistically significant effect on the shear bond strength ( $p<0.001)$, and the laser-treated group had a higher shear bond strength as compared to the sandblasting group. Type of bonding had a significant statistical effect on shear bond strength $(p=0.048)$. Also, the interaction between bonding and surface preparation showed no association between these two variables ( $p>0.05)$.

Table 1: Descriptive results of the shear bond strength of composite resin of the studied groups

\begin{tabular}{|c|c|c|c|c|}
\hline Groups & Average & $\begin{array}{l}\text { Standard } \\
\text { deviation }\end{array}$ & Minimum & Maximum \\
\hline $\begin{array}{l}\text { Single bond } \\
\text { universal + Laser }\end{array}$ & 20.60 & 5.23 & 14.27 & 31.87 \\
\hline $\begin{array}{l}\text { All bond universal } \\
+ \text { Laser }\end{array}$ & 21.09 & 4.21 & 12.77 & 29.28 \\
\hline G-premio + Laser & 25.58 & 4.82 & 16.24 & 31.83 \\
\hline $\begin{array}{l}\text { Single bond } \\
\text { universal }+ \\
\text { sandblast }\end{array}$ & 19.18 & 4.38 & 15.42 & 34.93 \\
\hline $\begin{array}{l}\text { All bond universal + } \\
\text { sandblast }\end{array}$ & 18.48 & 3.20 & 11.76 & 23.76 \\
\hline $\begin{array}{l}\text { G-premio + } \\
\text { sandblast }\end{array}$ & 19.01 & 5.04 & 11.76 & 30.73 \\
\hline
\end{tabular}

\begin{tabular}{|c|c|c|c|c|c|}
\hline Source & $\begin{array}{l}\text { Sum of } \\
\text { squares } \\
\text { as type } 3\end{array}$ & $\begin{array}{l}\text { Freedom } \\
\text { degree }\end{array}$ & Average & $\begin{array}{l}F \\
\text { Statistic }\end{array}$ & $P$ \\
\hline Width from origin & 40973.32 & 1 & 40973.32 & 1.99 & $>0.001$ \\
\hline $\begin{array}{l}\text { Surface } \\
\text { preparation }\end{array}$ & 299.73 & 1 & 299.73 & 14.58 & $>0.001$ \\
\hline Bonding type & 129.104 & 2 & 64.55 & 3.14 & 0.048 \\
\hline $\begin{array}{l}\text { Bonding type } \\
\text { * surface } \\
\text { preparation }\end{array}$ & 116.36 & 2 & 58.18 & 2.83 & 0.064 \\
\hline
\end{tabular}



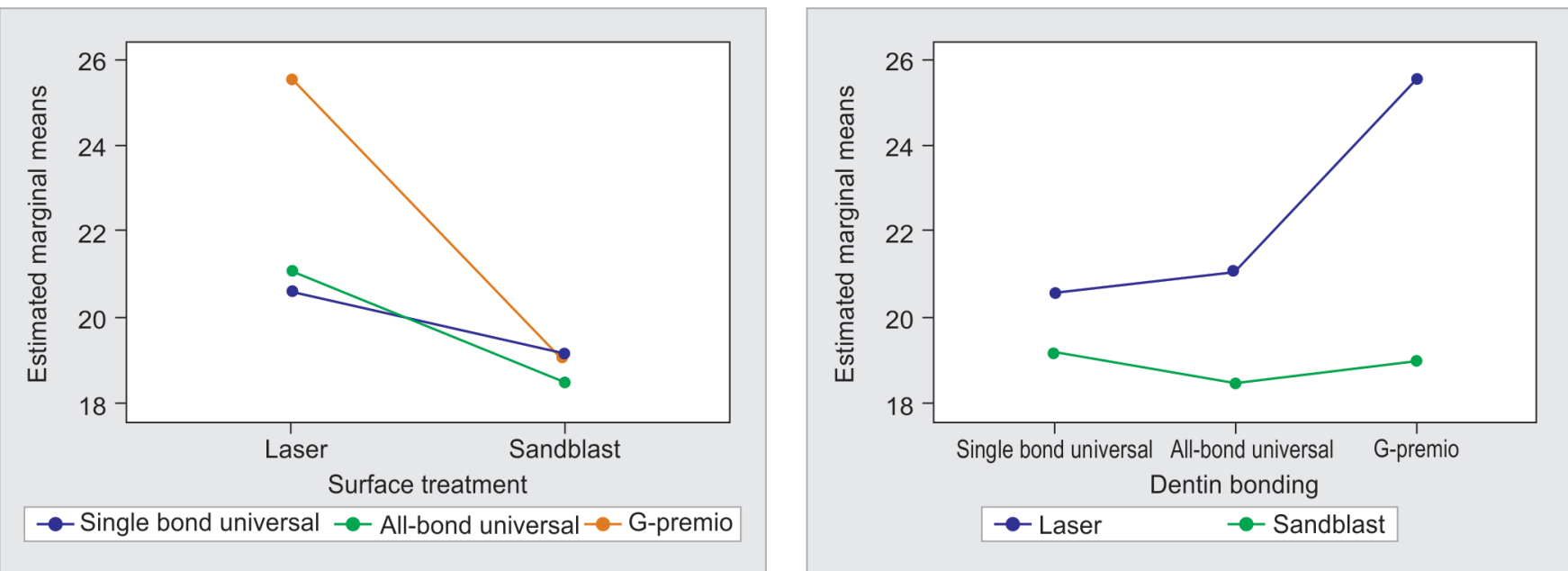

Graph 1A and B: (A) Estimated marginal means based on surface preparation method. (B) Estimated marginal means based on the type of bonding agent

\section{Estimated Marginal Means Assessment}

The results of estimated marginal means based on the surface preparation method and type of bonding agent are shown in Graph 1.

\section{Comparison of Strength According to the Type of Surface Preparation}

In this study, two surface preparation methods including sandblasting and Laser Er: YAG were used. The mean shear bond strength in the laser prepared group $(22.42 \pm$ 5.19) was significantly higher than that of the sandblasted group $(18.89 \pm 4.19)(\mathrm{p}<0.001)($ Graph 2$)$.

\section{Comparison of Shear Bond Strength in Sandblast Group According to Bonding Type}

In the sandblast group, three types of universal bonding were used: All-bond and G-Premio and single bond

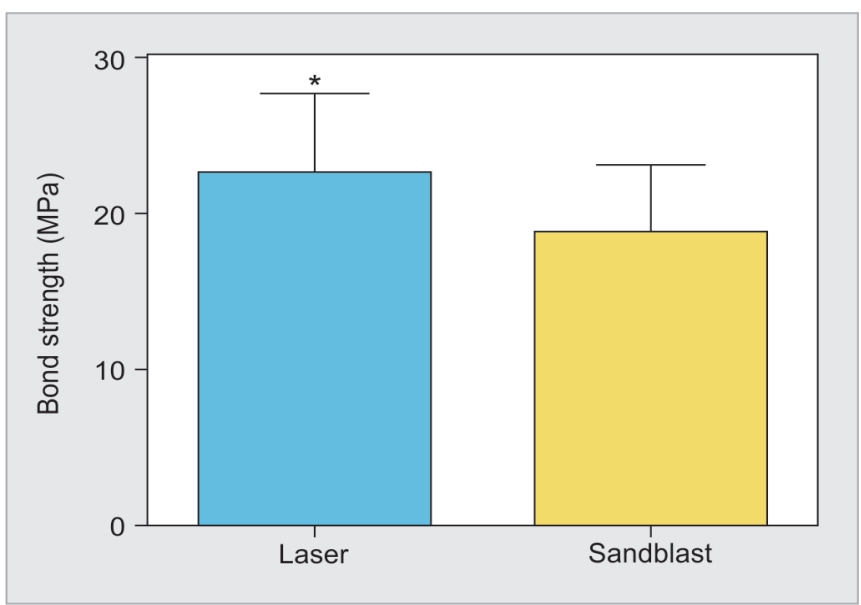

Fig. 2: Comparison between shear bond strength of laser and sandblast groups. Values are $\mathrm{M} \pm \mathrm{SD}$. *Significant statistically significant difference as compared to the sandblast group $(p<0.001)$. universal. Based on the results shown in Graph 3, in the sandblasting groups, the shear bond strength of composite resin in universal bonding: single bond universal(19.18 \pm 4.38 ).

All-bond $(18.48 \pm 3.2)$ and G-Premio $(19.01 \pm 5.04)$ did not show a statistically significant difference $(\mathrm{p}>$ 0.05) (Graph 3).

Also, as shown in Table 3, shear bond strengths were not statistically significant in any of the groups.

Table 3: Binary comparison of shear bond strength in sandblasted group according to bonding type, using Tukey test

\begin{tabular}{llll}
\hline Universal bonding group & $\begin{array}{l}\text { Average } \\
\text { difference }\end{array}$ & $\begin{array}{l}\text { Standard } \\
\text { deviation }\end{array}$ & $\begin{array}{l}P \text { - } \\
\text { value }\end{array}$ \\
\hline $\begin{array}{l}\text { Single bond universal by } \\
\text { universal All bond }\end{array}$ & 0.107 & 1.133 & 0.9 \\
$\begin{array}{l}\text { Single bond universal by } \\
\text { G-premio }\end{array}$ & -2.405 & 1.133 & 0.09 \\
$\begin{array}{l}\text { All bond universal by } \\
\text { G-premio }\end{array}$ & -2.512 & 1.133 & 0.07 \\
\hline
\end{tabular}

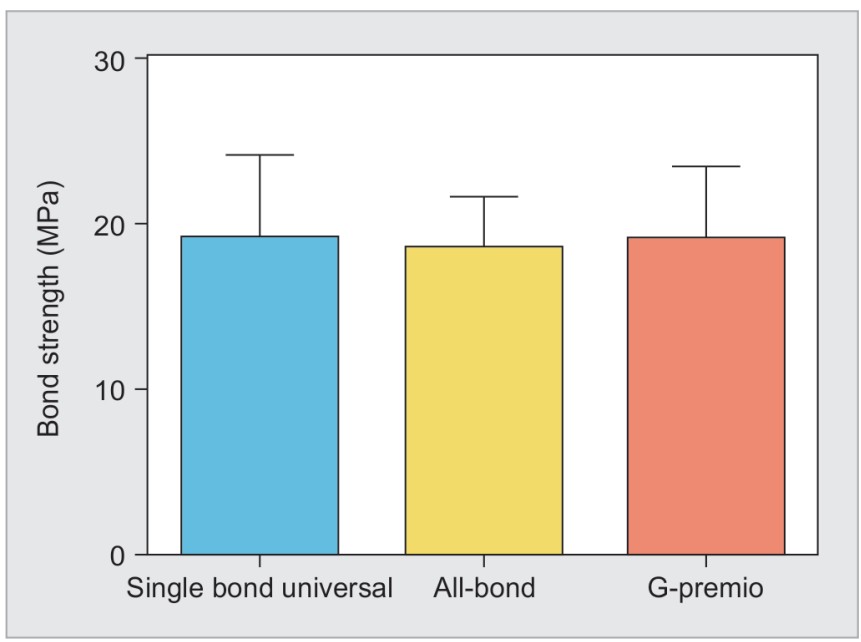

Graph 3: Comparison of shear bond strength of sandblast prepared groups according to the universal bonding type. Values are $\mathrm{M} \pm \mathrm{SD}$. 


\section{Comparison of Shear Bond Strength in Laser- treated Group Based on Type of Bonding}

In the laser-treated group, three types of universal bonding were used: All-bond, G-Premio and single bond universal. The results of the comparison of the shear bond strength of composite resin based on the type of universal bonding are shown in Graph 4. In the laser prepared groups, the shear bond strength of composite resin in the universal bonding $(25.58 \pm 4.82)$ with G-Premio when compared with single bond universal (20.6 \pm 5.23$)$ and all-bond (21.09 $\pm 4 / 21)$, was significantly higher (p $<0.001)$.

\section{All-bond and 3M Groups ( $p<0.05)$}

As shown in Graph 4, there was no statistically significant difference in shear bond strength between single bond universal and all bond universal, but there was a significant difference between the groups of single bond universal with G-Premio and all bond universal with G-Premio.

\section{Surface Preparation Images}

In this study, laser and sandblasting were used to prepare the surface. The results of SEM imaging in samples prepared with the laser, sandblast and samples

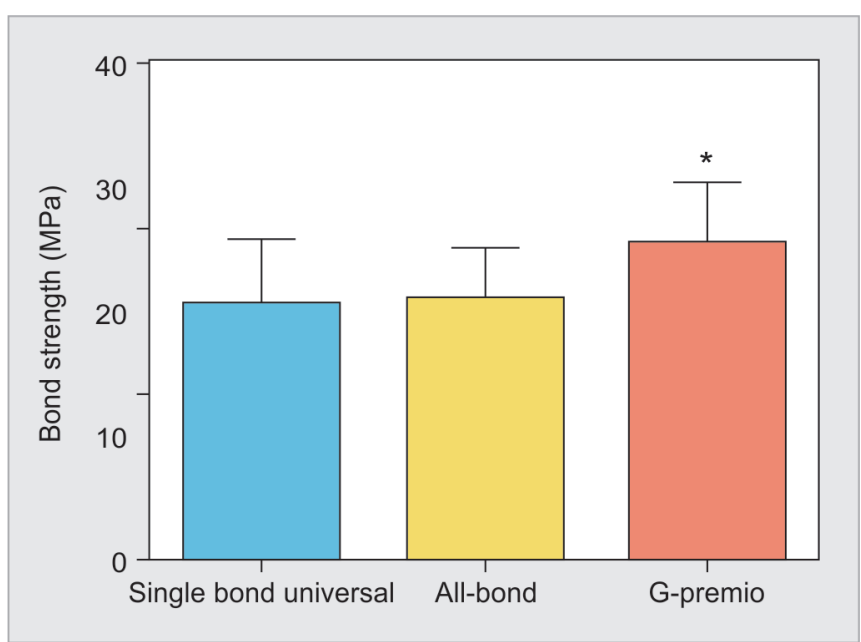

Graph 4: Comparison of shear bond strength of laser prepared groups in terms of universal bonding type. Values are $\mathrm{M} \pm \mathrm{SD}$. * Significant statistical differences were compared based on

without any preparation are shown in Figure 1A to $G$ respectively.

\section{DISCUSSION}

The esthetic and high strength of Zirconia ceramics has led to its increased usage in restorative dentistry. However, the poor bonding of ceramic restorations to composite resins is one of the challenges of the use of these restorations. Therefore, the application of methods
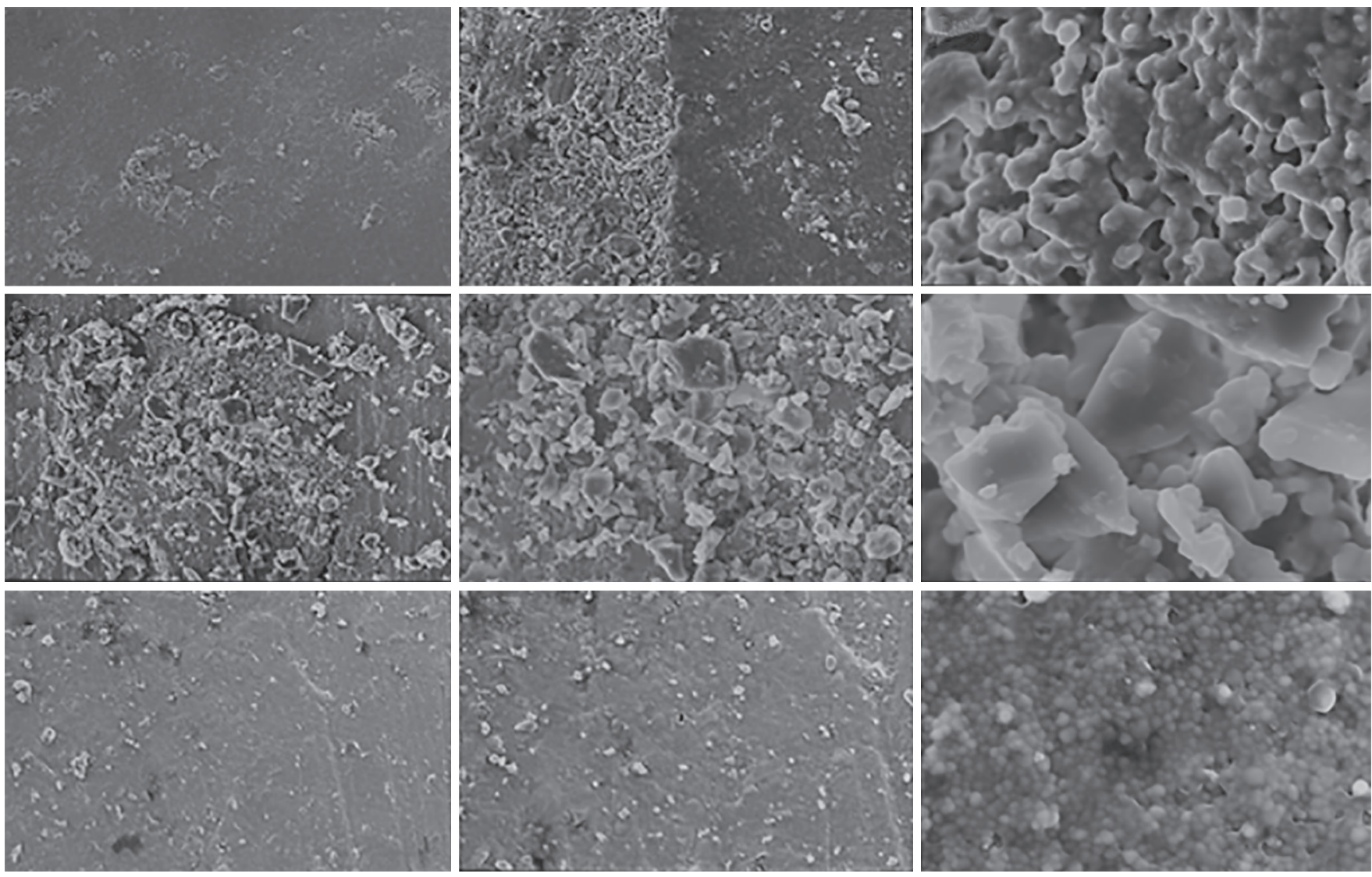

Figs 1A to G: (A) SEM image of samples prepared with aEr: YAG laser with magnitudes of 500-1000-5000, (B) SEM shape of sample prepared with sandblast with magnifications of 500-1000-5000 and (C) SEM shape of sample without any magnification preparation (500-1000-5000) 
Table 4: Binary comparison of shear bond strength in laserprepared group based on bonding type

\begin{tabular}{llll}
\hline $\begin{array}{l}\text { Groups of universal } \\
\text { bonding }\end{array}$ & $\begin{array}{l}\text { Difference } \\
\text { of average }\end{array}$ & $\begin{array}{l}\text { Standard } \\
\text { deviation }\end{array}$ & $P$-value \\
\hline $\begin{array}{l}\text { Single bond universal } \\
\text { by universal all bond }\end{array}$ & 0.107 & 1.133 & 0.92 \\
$\begin{array}{l}\text { Single bond universal } \\
\text { by G-premio }\end{array}$ & -2.405 & 1.133 & 0.03 \\
$\begin{array}{l}\text { All bond universal by } \\
\text { G-premio }\end{array}$ & -2.512 & 1.133 & 0.02 \\
\hline
\end{tabular}

that can strengthen the bond all ceramic and ceramic restorations of zirconia is one of the issues of interest to researchers. ${ }^{19}$

The aim of this study was to investigate the effect of laser Er: YAG, sandblasting and All-bond universal/ bisco, single bond universal/3M and G-Premio bond/ GC on the shear bond strength of zirconia ceramic to composite resin. The results showed that surface preparation using the laser as compared to sandblasting method significantly increased the shear bond strength of resin composite. The results of the study conducted by Akin and et $a .^{20}$ on the comparison of the effect of different lasers and sandblasting on the shear bond strength of resin composite with zirconia ceramics are similar to those of the current study.

The results of this study showed that the use of lasers Er: YAG (150 mJ, 10Hz and 20 seconds) and Neodymiumdoped yttrium aluminum garnet Nd: YAG (Neodymiumdoped yttrium aluminum garnet) increased the shear bond strength significantly as compared to the sandblasting method. The results of various studies indicate that there are several methods for bond strength between zirconia ceramics and resin composites. The underlying principle in all these methods is that the increase in surface roughness is one of the important factors in strengthening the aforementioned band. ${ }^{13}$ Sandblasting, together with the formation of surface roughness, causes a small gap in zirconia, which leads to undesirable changes in mechanical properties. ${ }^{21,22}$ Accordingly, the use of alternative methods instead of sandblasting attracted the attention of researchers and laser etchings were introduced to create surface roughness in zirconia. ${ }^{23}$ In another study by Akin et al., ${ }^{24}$ the effect of Er: YAG laser on the shear bond strength of zirconia ceramic to resin composite was evaluated and the results showed the level of surface roughness created at the prepared zirconium surface as compared to the zirconium prepared by sandblasting, and that the laser is significantly higher than the laser, which resulted in significant shear bond strength. A noticeable point is the time and power of the laser. Therefore, the Er: YAG laser with a lower power $(150 \mathrm{~mJ}$ and $10 \mathrm{~Hz})$ and a longer application time (20s) as compared to higherpower lasers $(200 \mathrm{~mJ}, 10 \mathrm{~Hz})$ and less time (5 seconds), increased the surface roughness. On the other hand, it reduced the formation of small gaps in ceramic zirconia. However, contrary to the results of the current study, the results obtained by Cavalcanti et al. ${ }^{25}$ showed that the shear bond strength from laser preparation (Er: YAG 200 $\mathrm{mJ}, 10 \mathrm{~Hz}$, and 5 seconds) was significantly less than that of sandblasting, and the strength of the samples prepared with this type of laser is even less than that of the control group. Similarly, Foxton et al. ${ }^{26}$ also showed that laser Er: YAG (200 mJ, $10 \mathrm{~Hz}, 5$ seconds) reduced the shear bond strength as compared to sandblasting and the control group. It seems that the contradiction in the results of the studies is due to differences in particle size and also the time for lasers use in the preparation.

In another study by Kasraei et al., the effect of $\mathrm{CO}_{2}$ and Er: YAG lasers on the shear bond strength of zirconia ceramic to resin composites was studied. The results of the study showed that both types of laser enhanced the shear bond strength. However, further evaluations showed that the $\mathrm{CO}_{2}$ laser is well absorbed in the zirconia ceramic surface, and, besides creating a surface roughness in the surface of the zirconia ceramic and increasing the bond strength, creates a series of fine cracks in the ceramic surface. ${ }^{27}$ However, the results of this study showed that the Er: YAG laser absorption rate was lower as compared to the $\mathrm{CO}_{2}$ laser, and in order to absorb more of it in the zirconia ceramic surface, graphite powder was used and the important point in this study is that the laser Er: YAG enhances surface roughness without causing any crack in the ceramic surface of zirconia. For this reason, there is a significant increase in the shear bond strength. In fact, this justifies the further increase in the shear bond strength of ceramics prepared with Er: YAG laser when compared with the sandblast group in the current study.

In the present study, the effect of universal bonding type on the shear bond strength of zirconia ceramic to resin composite was investigated. The results showed that in the sandblast group, type of universal bonding had no significant effect on bond strength shear, while in the group prepared with laser G-Premiob and/GC, there was significant increase in shear bond strength as compared to Universal All-bond/Bisco and 3M Single bond universal. Although a study similar to the current one has not been conducted so far, the results of various studies on the effect of universal bonding on the shear bond strength are somewhat contradictory. In the study conducted by Poggio et al., ${ }^{28}$ with regards to the effect of dentin preparation on universal adhesive strength, five different types of universal bonding's including Futurabond M, Scotchbond Universal, Clearfil Universal Bond, G-Premio Bond and Peak Universal Bond were used. The results of the study showed that the type of 
universal bonding has no significant effect on the shear bond strength of the composite resin.

A remarkable point in this study is that in the case of glycine-based surface preparation, shear bond strength increased significantly only in the presence of universal G-Premio adhesive (and no other adhesives). What justifies the significant effect of Universal G-Premio bonding in the presence of glycine, on the increase in bond strength, is the low $\mathrm{pH}$ of this bonding. However, how the low $\mathrm{pH}$ enhances the bond strength is still not clear. ${ }^{28}$ In the study conducted by Solan et al., ${ }^{29}$ the ability of universal bonding used in various substrates such as dentin, composite, porcelain and enamel using etching and rinsing and self-etching methods was compared using, Scotchbond Universal 3M ESPE, Scotchbond Multipurpose, single bond 2, Clearfil SE Bond Scotch bond multipurpose. The result of this study showed that the overall ability of universal adhesive bonding is significantly higher than that of other bonding, although the type of substrate is also effective in bond strength. Inversely, in the study of Suzuki et al., ${ }^{30}$ the shear bond strength of universal adhesives (including Scotchbond Universal, G-Premio bond, and All-bond Universal) with a conventional two-step self-etch adhesive, Clearfil SE bond was investigated. The result shows that the shear bond strength of universal adhesives was significantly lower than two-step self-etch adhesive. In another study, the shear bond strength of universal adhesives (Single Bond Universal and Tetric N Bond Universal) with Clearfil SE adhesive as control were investigated. Regarding shear bond strength, results have demonstrated that Clearfil self-etch adhesive has superior bond strengths compared with Universal adhesives. ${ }^{31}$

The results of studies show that substrate type is one of the factors that affect adhesive bonding. ${ }^{32}$ In fact, the chemical properties of a substrate, which may be dental tissue or restorative materials, has an effect on the type of adhesive applied and the amount of strength it produces. For example, dentin has a complex structure which is moist and therefore requires the use of hydrophilic and hydrophobic materials, while enamel only requires the use of hydrophobic materials because its composition is more inorganic. ${ }^{32,33}$ Based on this, it seems that the difference in the type of substrate is one of the causes of variation in the results of various studies.

One limitation of this study is that in vitro procedure, even if crucial to rapidly assess the bonding efficacy of newly developed adhesives, it is not fully valid and comparable to clinical trials. Another limitation of this study is that the small number of samples limits the interpretation of the results. Also, the limited application of Er: YAG laser power and exposure time are the other restriction of this study. Further investigation should focus on an increased number of samples per group with different laser power and exposure time when evaluating the shear bond strength in vitro and in vivo condition

\section{CONCLUSION}

In this study, the effect of surface preparation with sandblasting and laser, as well as three types of universal bonding on the shear bond strength of zirconia ceramic to the composite resin was studied. The results showed that the use of laser in surface preparation as compared to sandblasting is a more appropriate method for increasing bond strength, and on the other hand, G-Premio/GC universal bonding agent can be a suitable candidate for bond strength enhancement.

\section{ACKNOWLEDGEMENT}

The authors are grateful to the Research Assistant, Dental Research Center, Hamadan University of Medical Sciences, for supporting this thesis.

\section{REFERENCES}

1. Atsu SS, Kilicarslan MA, Kucukesmen HC, Aka PS. Effect of zirconium-oxide ceramic surface treatments on the bond strength to adhesive resin. J Prosthet Dent. 2006 June;95(6):430-6.

2. Christel P, Meunier A, Heller M, Torre JP, Peille CN. Mechanical properties and short-term in-vivo evaluation of yttrium-oxide-partially-stabilized zirconia. J Biomed Mater Res. 1989 January;23(1):45-61.

3. Blatz MB, Sadan A, Martin J, Lang B. In vitro evaluation of shear bond strengths of resin to densely-sintered highpurity zirconium-oxide ceramic after long-term storage and thermal cycling. J Prosthet Dent. 2004 June;91(4):356-62.

4. Piwowarczyk A, Lauer HC, Sorensen JA. The shear bond strength between luting cements and zirconia ceramics after two pre-treatments. Oper Dent. 2005 June;30(3):382-8.

5. Rosenstiel SF, Land MF, Crispin BJ. Dental luting agents: A review of the current literature. J Prosthet Dent. 1998 September;80(3):280-301.

6. Blatz MB. Adhesive cementation of high-strength ceramics. J Esthet Restor Dent. 2007 September 14;19(5):238-9.

7. El-Shrkawy ZR, El-Hosary MM, Saleh O, Mandour MH. Effect of different surface treatments on bond strength, surface and microscopic structure of zirconia ceramic. FDJ. 2016 June;2(1):41-53.

8. Ozcan M, Barbosa SH, Melo RM, Galhano GA, Bottino MA. Effect of surface conditioning methods on the microtensile bond strength of resin composite to composite after aging conditions. Dent Mater J. 2007 October;23(10):1276-82.

9. Lucena-Martin C, Gonzalez-Lopez S, Navajas-Rodriguez de Mondelo JM. The effect of various surface treatments and bonding agents on the repaired strength of heattreated composites. J Prosthet Dent. 2001 November;86(5): 481-8.

10. Armengol V, Laboux O, Weiss P, Jean A, Hamel H. Effects of Er:YAG and Nd:YAP laser irradiation on the surface 
roughness and free surface energy of enamel and dentin: an in vitro study. Oper Dent. 2003 January;28(1):67-74.

11. Trajtenberg CP, Pereira PN, Powers JM. Resin bond strength and micromorphology of human teeth prepared with an Erbium:YAG laser. Am J Dent. 2004 October 1;17(5):331-6.

12. Kumbuloglu O, Lassila LV, User A, Vallittu PK. Bonding of resin composite luting cements to zirconium oxide by two air-particle abrasion methods. Oper Dent. 2006 February; 31(2):248-55.

13. Wolfart M, Lehmann F, Wolfart S, Kern M. Durability of the resin bond strength to zirconia ceramic after using different surface conditioning methods. Dent Mater : official publication of the Academy of Dental Materials. 2007 January;23(1):45-50.

14. Della Bona A, Anusavice KJ. Microstructure, composition, and etching topography of dental ceramics. Int J Prosthodont. 2002 April;15(2):159-67.

15. Sofan E, Sofan A, Palaia G, Tenore G, Romeo U, Migliau G. Classification review of dental adhesive systems: from the IV generation to the universal type. Ann Stomatol. 2017 January;8(1):1-17.

16. Rosa WL, Piva E, Silva AF. Bond strength of universal adhesives: A systematic review and meta-analysis. J Dent. 2015 July;43(7):765-76.

17. Arami S, Hasani Tabatabaei M, Namdar F, Safavi N, Chiniforush N. Shear Bond Strength of the Repair Composite Resin to Zirconia Ceramic by Different Surface Treatment. J Lasers Med Sci. 2014 Autumn;5(4):171-5.

18. Bona AD, Borba M, Benetti P, Cecchetti D. Effect of surface treatments on the bond strength of a zirconiareinforced ceramic to composite resin. Braz Oral Res. 2007 March;21(1):10-5.

19. Abd El-Ghany OS, Sherief AH. Zirconia based ceramics, some clinical and biological aspects: Review. FDJ. 2016 December;2(2):55-64.

20. Akin H, Ozkurt Z, Kirmali O, Kazazoglu E, Ozdemir AK. Shear bond strength of resin cement to zirconia ceramic after aluminum oxide sandblasting and various laser treatments. Photomed Laser Surg. 2011 Decembre;29(12):797-802.

21. Karakoca S, Yilmaz H. Influence of surface treatments on surface roughness, phase transformation, and biaxial flexural strength of Y-TZP ceramics. J Biomed Mater Res B Appl Biomater. 2009 July;91(2):930-7.

22. Yun JY, Ha SR, Lee JB, Kim SH. Effect of sandblasting and various metal primers on the shear bond strength of resin cement to Y-TZP ceramic. Dent Mater. 2010 July;26(7): 650-8.

23. Paranhos MP, Burnett LH, Jr., Magne P. Effect Of Nd:YAG laser and $\mathrm{CO} 2$ laser treatment on the resin bond strength to zirconia ceramic. Quintessence Int. 2011 May;42(1): 79-89.

24. Akin H, Tugut F, Akin GE, Guney U, Mutaf B. Effect of Er:YAG laser application on the shear bond strength and microleakage between resin cements and Y-TZP ceramics. Lasers Med Sci. 2012 January;27(2):333-8.

25. Cavalcanti AN, Foxton RM, Watson TF, Oliveira MT, Giannini M, Marchi GM. Bond strength of resin cements to a zirconia ceramic with different surface treatments. Oper Dent. 2009 May;34(3):280-7.

26. Foxton RM, Cavalcanti AN, Nakajima M, Pilecki P, Sherriff $\mathrm{M}$, Melo L, et al. Durability of resin cement bond to aluminium oxide and zirconia ceramics after air abrasion and laser treatment. J Prosthodont 2011 February;20(2): 84-92.

27. Kasraei S, Rezaei-Soufi L, Heidari B, Vafaee F. Bond strength of resin cement to CO2 and Er: YAG laser-treated zirconia ceramic. Restor Dent Endod. 2014 November;39(4):296302.

28. Poggio C, Beltrami R, Colombo M, Chiesa M, Scribante A. Influence of dentin pretreatment on bond strength of universal adhesives. Acta Biomater Odontol Scand. 2017 March;3(1):30-5.

29. Isolan CP, Valente LL, Münchow EA, Basso GR, Pimentel AH, Schwantz JK, et al. Bond strength of a universal bonding agent and other contemporary dental adhesives applied on enamel, dentin, composite, and porcelain. Applied Adhesion Science. 2014 December;2(1):25.

30. Suzuki S, Takamizawa T, Imai A, Tsujimoto A, Sai K, Takimoto $\mathrm{M}$, et al. Bond durability of universal adhesive to bovine enamel using self-etch mode. Clin Oral Investig. 2018 April;22(3):1113-1122.

31. Jayasheel A, Niranjan N, Pamidi H, Suryakanth MB. Comparative Evaluation of shear Bond Strength of universal Dental Adhesives-An in vitro study. J Clin Exp Dent. 2017 July;9(7):e892.

32. Pashley DH, Tay FR, Breschi L, Tjaderhane L, Carvalho RM, Carrilho M, et al. State of the art etch-and-rinse adhesives. Dent Mater. 2011 January;27(1):1-16.

33. Van Meerbeek B, Yoshihara K, Yoshida Y, Mine A, De Munck J, Van Landuyt KL. State of the art of self-etch adhesives. Dent Mater. 2011 January;27(1):17-28. 